\title{
Effect of purge air on rotor endwall heat transfer of an axial turbine
}

\section{Original article}

Article history:

Accepted: 22 August 2017

Published: 12 October 2017

This paper is the updated version of a paper originally presented at the 1st Global Power and Propulsion Forum, GPPF 2017, in Zurich, Jan 16-18 2017

\section{Check for updates}

*Correspondence:

SLG: lazzigas@ethz.ch

Peer review:

Single blind

\section{Copyright:}

(ㄷ) 2017 Lazzi Gazzini et al. () This is an open access article distributed under the Creative Commons Attribution Non Commercial No Derivatives License (CC BY-NC-ND 4.0). Unrestricted use, distribution, and reproduction of the original work are permitted for noncommercial purposes only, provided it is properly cited and its authors credited. No derivative of this work may be distributed.

\section{Keywords:}

heat transfer; purge flow; infrared thermography; rotor; endwall

\section{Citation:}

Lazzi Gazzini S., Schädler R., Kalfas A. I., Abhari R. S., Hohenstein S., et al. (2017). Effect of purge air on rotor endwall heat transfer of an axial turbine. Journal of the Global Power and Propulsion Society. 1: $211-223$. https://doi.org/10.22261/F29ZWY
Sebastiano Lazzi Gazzini1 ${ }^{1, *}$, Rainer Schädler ${ }^{1}$, Anestis I. Kalfas ${ }^{2}$, Reza S. Abhari', Sebastian Hohenstein ${ }^{3}$, Gregor Schmid ${ }^{3}$, Ewald Lutum ${ }^{4}$

${ }^{1}$ LEC ETH Zürich, ML J 41.2, Sonneggstrasse 3, CH-8092 Zürich,

Switzerland

${ }^{2}$ Aristotle University of Thessaloniki, Thessaloniki 541 24, Greece

${ }^{3}$ Siemens AG, Mellinghofer Str. 55, 45473 Mülheim an der Ruhr,

Germany

${ }^{4}$ MTU AeroEngines AG, Dachauer Str. 665, 80995 München, Germany

\begin{abstract}
In order to gain in cycle efficiency, turbine inlet temperatures tend to rise, posing the challenge for designers to cool components more effectively. Purge flow injection through the rim seal is regularly used in gas turbines to limit the ingestion of hot air in the cavities and prevent overheating of the disks and shaft bearings. The interaction of the purge air with the main flow and the static pressure field of the blade rows results in a nonhomogenous distribution of coolant on the passage endwall which poses questions on its effect on endwall heat transfer. A novel measurement technique based on infrared thermography has been applied in the rotating axial turbine research facility LISA of the Laboratory for Energy Conversion (LEC) of ETH Zürich. A 1.5 stage configuration with fully three-dimensional airfoils and endwall contouring is integrated in the facility. The effect of different purge air mass flow rates on the distribution of the heat transfer quantities has been observed for the rated operating condition of the turbine. Two-dimensional distributions of Nusselt number and adiabatic wall temperature show that the purge flow affects local heat loads. It does so by acting on the adiabatic wall temperature on the suction side of the passage until $30 \%$ of the axial extent of the rotor endwall. This suggests the possibility of effectively employing purge air also as rotor platform coolant in this specific region. The strengthening of the secondary flows due to purge air injection is observed, but plays a negligible role in varying local heat fluxes. For one test case, experimental data is compared to highfidelity, unsteady Reynolds-Averaged Navier-Stokes simulations performed on a model of the full 1.5 stage configuration.
\end{abstract}




\section{Introduction}

In turbomachinery applications, air is spilled from the upstream compressor and bled through the cavities separating stators and rotors of the turbine stages to prevent ingestion of hot gas below the platforms. This avoids the consequent overheating of the disk and bearings. When injected into the mainstream, purge flow can also be used to cool the rotor platform, but the non-uniformity of the static pressure field at the cavity exit and the interaction with the secondary flows limit its effectiveness. The mechanisms responsible for this are well documented in several computational and experimental works.

Paniagua et al. (2004) compare experimental data and numerical predictions and verify that the purge flow is entrained by the rotor hub passage vortex, increasing its intensity and promoting its lift-off from the platform. The impact of mixing losses and increased secondary flows due to the injection of cavity flow is found to be of the same order by Reid et al. (2006). Schuepbach et al. (2010) confirm that the circulation of the hub passage vortex is increased by the entrainment of purge flow. The strengthening of the secondary flows is attributed to the negative incidence of the rim seal leakage flow by Ong et al. (2012). They observe that the entrainment of the purge air into the secondary flows facilitates its migration towards higher span-wise locations and removes it from the endwall, thus limiting its effectiveness as coolant. The preferential injection of the leakage flow towards the suction side of the blade is also clearly visualized.

Consistent considerations are reported by Jenny et al. (2013), when studying the interaction of purge air with the mainstream on a turbine with contoured endwalls. A thorough computational aerodynamic investigation is accomplished by Green et al. (2013b). Their findings are validated experimentally (Green et al., 2013a) and comprehensively summarize and link the mechanisms regulating purge flow injection and its interaction with the main flow. For the turbine studied, the adhesion of purge air is limited to the proximity of the suction side of the blade until $20 \%$ of the wetted surface.

As far as the cooling effectiveness of the rim seal leakage flow and its impact on heat transfer are concerned, several experiments can be found in literature, mainly from linear cascades. One of the earliest works in this regard was published by Blair (1974). Coolant is observed to be swept towards the suction side of the passage. The resolution of the method was later improved by Graziani et al. (1980). Consistently, Gao et al. (2009) demonstrate that purge flow can be effective in cooling the front portion of the passage and visualize the leakage flow moving towards the suction side of the blade. Similar observations are made by Wright et al. (2009).

High-resolution data is provided in Lynch and Thole (2015) by means of IR Thermography on a cascade presenting endwall contouring. They report an increase of the heat transfer on the suction side of the passage with higher leakage flow injection. The technique is similar to the one used in the present paper, as it relies on a contoured endwall heater (developed by Lynch et al. [2011]) and on infrared imaging.

Data from rotating facilities is not as readily available due to the technical challenges of measuring on the rotating frame. Blair (1992) uses iso-flux foils and arrays of thermocouples to measure heat transfer contours in a low-speed facility. Time-resolved heat transfer and film cooling measurements in shortduration facilities are found in literature, but are often taken at discrete locations (e.g., by means of heat flux gauges). Examples are the early works by Abhari et al. (1991), Abhari and Epstein (1992) and Dunn et al. (1984a). More recently, Dénos and Paniagua (2002) find a reduction in gas temperature due to purge flow injection, again on the suction side of the passage.

Aim of the current work is to observe the effect of realistic rim seal leakage flows on the rotor endwall heat transfer with high-resolution data acquired on the rotating frame of reference. Complemented with unsteady Computational Fluid Dynamics (CFD) predictions, the experimental results are interpreted with reference to the interaction of the purge flow with the hub endwall secondary flows. 


\section{Methodology}

\section{Experimental setup}

The axial turbine research facility LISA of the Laboratory for Energy Conversion (LEC) at ETH Zürich is a long-duration, moderate-speed, low-temperature rotating facility. It consists of a quasiclosed air loop including a centrifugal compressor, a two-stage heat exchanger, a $3 \mathrm{~m}$-long flow conditioning stretch for flow uniformity upstream of the turbine, the turbine itself and a calibrated Venturi nozzle for mass flow measurements. The flow undergoes an acceleration upstream of the turbine stage, thus reducing further the impact of any non-uniformities left after the conditioning stretch. The heat exchanger controls the turbine inlet total temperature $T_{t, \text { in }}$ to an accuracy of $\pm 0.3 \mathrm{~K}$.

A DC generator, coupled to the turbine shaft via a gearbox, acts as break by converting the mechanical power produced by the turbine into electrical power, which is fed back to the grid. The rotational speed is controlled with an accuracy of $\pm 0.02 \%( \pm 0.5 \mathrm{rpm})$. A torque meter is installed on the vertical shaft between the turbine and the gearbox. At the exit of the test section, two successive rows of deswirl vanes recover the static pressure before going through the venturi nozzle and back to the compressor. For more details on the rig the reader is referred to Schuepbach et al. (2010).

A 1.5 stage, high work turbine configuration is installed in the test section of the facility. Both airfoils and endwalls have a complex 3D geometry optimized for minimizing the aerodynamic losses.

Air is spilled from the main air loop upstream of the flow conditioning stretch and fed to the stator/ rotor cavity through the first stator vanes. The amount of by-pass flow "B" (see Figure 1) is measured via a standard nozzle. The purge flow mass flow rate is calculated as the difference between the total by-pass mass flow rate and the secondary leakage flow following the path through the drum, labeled " $S$ " in Figure 1. The injection ratio (IR) is then defined as:

$$
\mathrm{IR}=\frac{\dot{\mathrm{m}}_{\mathrm{B}}-\dot{\mathrm{m}}_{\mathrm{S}}}{\dot{\mathrm{m}}_{\mathrm{MAIN}}} \cdot 100,
$$

where $\dot{m}_{S}$ is measured by another standard nozzle. The error on the IR is of $\pm 0.01 \%$. A $45^{\circ}$ chamfer on the rotor platform ensures that the purge flow presents an axial component of velocity, relevant for endwall cooling purposes (Paniagua et al., 2004). Further details on the purge injection system are found in Regina et al. (2014) and Schädler et al. (2016).

The facility is set up for heat transfer measurements on the rotor by adapting the infrared-based technique used by Laveau et al. (2014) for stationary parts.

A FLIR SC7300L IR camera records thermograms of the rotor endwall through three IR-transparent $\mathrm{ZnSe}$ (Zinc-Selenide) windows mounted on the rotor casing (schematically shown in Figure 1). The camera can be traversed to access more of the inlet portion of the passage.

A controlled thermal boundary condition on the rotor hub endwall surface is achieved by installing a thermally insulating insert (Polyether-ether-ketone or PEEK) in the platform. The insert is instrumented with a film heater deposited on the endwall surface and 9 PT100 RTDs embedded in the substrate, $1.5 \mathrm{~mm}$ below the endwall surface, to monitor the conductive heat losses. The heater is obtained by directly depositing a metallic multilayer $(10 \mathrm{~nm} \mathrm{Cr}, 200 \mathrm{~nm} \mathrm{Ni}, 10 \mathrm{~nm} \mathrm{Au}$ ) on the CNCmachined PEEK insert by e-beam physical vapour deposition and then by laser cutting the film. A serpentine of uniform width of $1.65 \mathrm{~mm}$ is produced with a gap between tracks of $55 \mu \mathrm{m}$. Highemissivity paint $(\varepsilon=0.98)$ is applied on the whole rotor to allow for accurate temperature measurements and minimize spurious reflections. A correction factor $S_{\mathrm{q}}$ for local heat flux non-uniformities is applied to the nominal value of average heat flux produced by the heater based on the results of stepwise transient heating tests. The electrical heat flux generated by Joule effect is then calculated as:

$$
\dot{\mathrm{q}}_{\mathrm{el}}=\mathrm{S}_{\mathrm{q}} \frac{\mathrm{P}}{\mathrm{A}}
$$




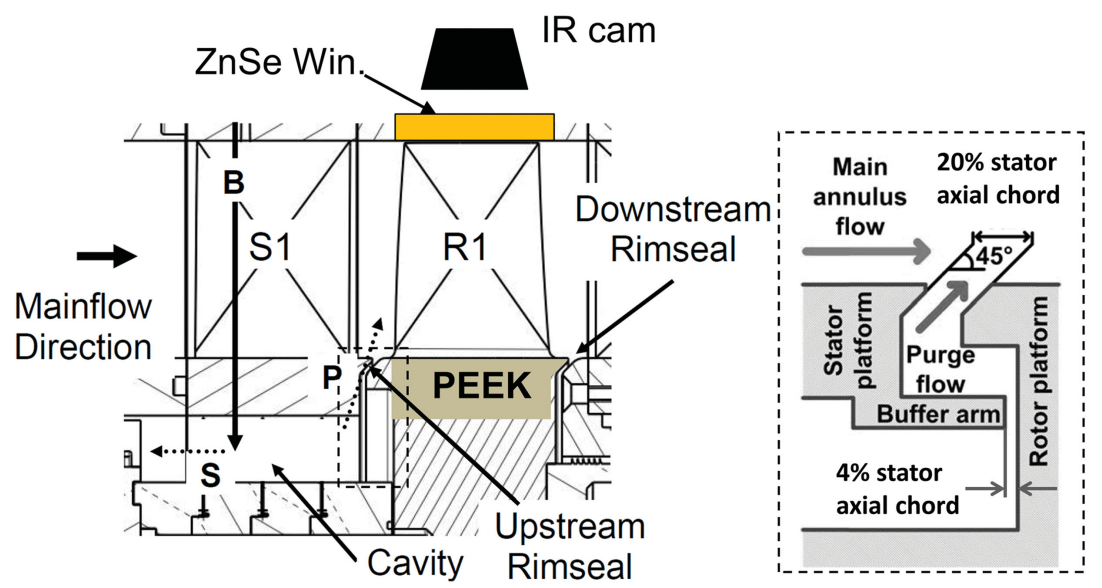

Figure 1. View from an axial plane of the purge flow path (left). A schematic of the optical setup is included; detail of the stator-rotor rim seal cavity (right).

Where $\mathrm{P}=\mathrm{i} \cdot \mathrm{V}$ is the electrical power fed to the heater and $\mathrm{A}$ is the surface area of the hub endwall. The signal from the PT100 is read out by an on-board data acquisition system sending the readings to a computer via Wi-Fi. The resulting solid temperatures have an error of $\pm 0.5 \mathrm{~K}$.

Power is fed to the data acquisition system and to the heater separately through a two-channel slip ring. The DC power sent to the heater is measured with a voltmeter and an ammeter with an uncertainty of less than $\pm 1.6 \%$.

\section{Measurement procedure}

Measurements are performed at steady state for the nominal operating conditions for the rig, summarized in Table 1. The infrared camera records sequences of 1,000 images with two different integration times $(10 \mu \mathrm{s}$ and $50 \mu \mathrm{s})$, for two camera positions and four power settings of the heater. In total, each test case comprises of 16,000 images. The acquisition of a frame is triggered once per revolution by the signal coming from an optical tachometer. The two distinct views of the endwall allows for the covering of the inlet portion of the endwall passage until $\sim 80 \%$ of its axial extent.

Table 1. Operating conditions of the rig.

\begin{tabular}{|l|c|}
\hline & Rig operating conditions \\
\hline Total rotor relative inlet temperature $T_{t, r e l}$ & $313.8 \mathrm{~K}$ \\
\hline Stage pressure ratio & $1.65 \pm 0.4 \%$ \\
\hline Rotor inlet Mach number & 0.26 \\
\hline Reynolds number at R exit- $\operatorname{Re}_{\text {Cax }}$ & $510 \mathrm{k}$ \\
\hline Rotor speed & $2,700 \mathrm{rpm}$ \\
\hline Mass flow & $11.7 \mathrm{~kg} / \mathrm{s}$ \\
\hline Injection ratio & $0.0 \% / 0.8 \% / 1.2 \%$ \\
\hline
\end{tabular}


Once an infrared camera acquisition is completed, the electrical power fed to the heater is increased to the next level. The average heat flux produced by the endwall heater ranges from $1.4 \mathrm{~kW} / \mathrm{m}^{2}$ to $8.1 \mathrm{~kW} / \mathrm{m}^{2}$. The different views of the passage are mapped onto a mesh of the rotor endwall by means of projective geometry as explained by Laveau et al. (2014). Further details on the geometrical transformation of the images can be found in Faugeras et al. (2004). The long and short exposure data sets are combined after registration and deblurring to produce a high-dynamic range picture of the thermal field. The resolution of the final thermograms is of $0.36 \mathrm{~mm} /$ pixels, but due to the movement of the rotor during the integration time, the temperature contours are smeared over $0.97 \mathrm{~mm}$ in the circumferential direction.

Feeding current and voltage are constantly monitored, while the solid temperature is recorded in bursts of $5 \mathrm{~s}$ during the infrared camera acquisitions.

\section{Calculation of the heat transfer quantities}

The calculation of the convective heat flux $\dot{\mathrm{q}}_{\text {conv }}$ is based on the following energy balance:

$$
\dot{\mathrm{q}}_{\text {el }}-\dot{\mathrm{q}}_{\text {cond }}-\dot{\mathrm{q}}_{\text {rad }}=\dot{\mathrm{q}}_{\text {conv }}
$$

Where $\dot{q}_{\text {el }}$ is the electrical heat flux produced by Joule heating returned by Equation 2, $\dot{q} "$ cond is the conductive heat loss in the substrate and $\dot{\mathrm{q}}_{\text {rad }}$ is the radiative heat transfer to the environment evaluated according to:

$$
\dot{\mathrm{q}}_{\mathrm{rad}}=\varepsilon \cdot \sigma \cdot\left(\mathrm{T}_{\mathrm{w}}^{4}-\mathrm{T}_{\mathrm{t}, \mathrm{rel})}^{4}\right.
$$

With $\varepsilon$ being the emissivity of the surface, $\sigma$ the Stefan-Boltzmann constant, $T_{w}$ the wall temperature and $T_{t, \text { rel }}$ the rotor-relative total temperature at the rotor inlet, here taken as a reference temperature for the heat transfer by radiation. The conductive heat loss $\dot{q}_{\text {cond }}$ is evaluated based on the readings of the 9 PT100 RTDs and the thermal properties of the substrate according to the following 1D equation:

$$
\dot{\mathrm{q}}_{\text {cond }}^{\prime \prime}=\frac{\mathrm{k}_{\text {sub }}}{\mathrm{d}_{\text {sub }}} \cdot\left(\mathrm{T}_{\mathrm{w}}-\mathrm{T}_{\text {sub }}\right)
$$

In Equation 5, $\mathrm{T}_{\mathrm{w}}$ is the wall temperature measured at the normal projection on the endwall of the PT100 location and $T_{\text {sub }}$ is the substrate temperature read by the PT100 thermometer. For each heat flux level, an average value of conductive loss is calculated over the passage and used in the energy balance of Equation 3. The average values fall between $1.6 \%$ and $6.8 \%$.

Finally, the convective heat flux $\dot{\mathrm{q}}_{\text {conv }}$ is obtained and the heat transfer coefficient $\mathrm{h}$ and the adiabatic wall temperature $T_{a w}$ can be determined. A linear fit is performed through the four data points available for each location on the endwall mesh, being valid the following:

$$
\dot{\mathrm{q}}_{\text {conv }}=\mathrm{h} \cdot\left(\mathrm{T}_{\mathrm{w}}-\mathrm{T}_{\mathrm{aw}}\right) \text {. }
$$

The linear fitting procedure is illustrated in Figure 2.

The heat transfer coefficient corresponds to the slope of the lines, while the intercept at $\dot{\mathrm{q}}_{\text {conv }}=0$ is the adiabatic wall temperature. The linearity of the convective heat flux with the wall temperature is highlighted. The locations labelled with numbers $1-4$ are marked in the endwall map of Figure $3 \mathrm{a}$.

\section{Computational setup}

Transient CFD simulations were performed on a $20^{\circ}$ sector of the complete 1.5 stage turbine, including the hub cavity. The mesh was generated in AutoGrid5 $5^{\mathrm{TM}}$ by Numeca. Approximately $2 \mathrm{M}$ cells were used for each passage with an average $\mathrm{y}^{+}<1$. The simulations were conducted in ANSYS CFX v15.0 with experimental boundary conditions: 


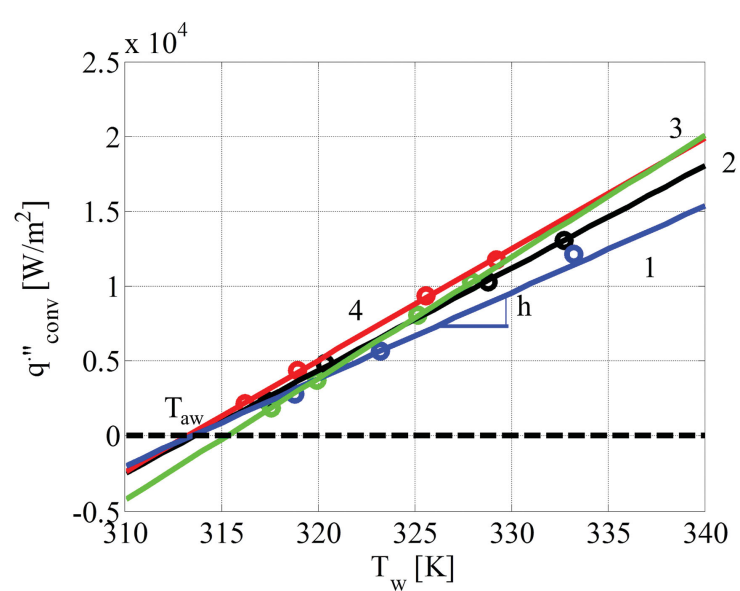

Figure 2. Linear fit procedure to calculate heat transfer coefficient $\mathrm{h}$ (slope) and adiabatic wall temperature Taw (intercept).

Locations 1-4 are shown in Figure 3a.

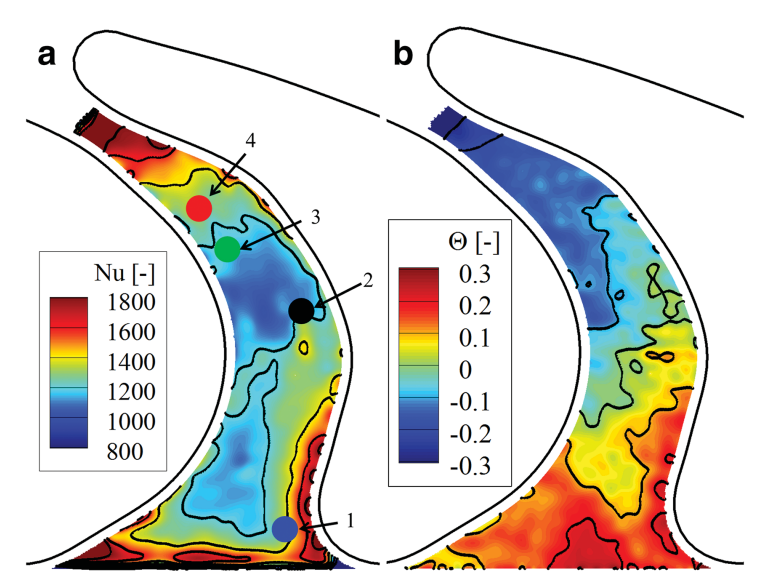

Figure 3. a) Nusselt number distribution for the reference case, nominal operating condition with no purge flow injection; b) distribution of non-dimensional adiabatic wall temperature Equation 7.

- $\quad$ total pressure and total temperature at the inlet;

- $\quad$ static pressure at the outlet;

- $\quad$ an IR $=0.8 \%$ for the cavity flow;

- two uniform endwall heat flux values for the Nusselt number calculation;

- $\quad$ an endwall equivalent sandgrain roughness of $\mathrm{k}_{\mathrm{s}}=12 \mu \mathrm{m}$, representative of the the high-emissivity coating.

The Shear Stress Transport turbulence model and a temporal resolution of 50 time steps per rotor pitch were used. Three complete rotor revolutions ensure a converged aerodynamic flow field with adiabatic walls. An additional revolution was then conducted for each of the two wall heat flux boundary conditions. The results shown are derived from data that was time-averaged over this last revolution.

For comparison, also a steady state result is shown, derived from a mixing plane model. Mesh, boundary conditions and turbulence settings are identical to the transient setup.

\section{Results and discussion}

Distributions of measured heat transfer quantities on the rotor endwall are shown for the reference case: nominal operating condition of the facility with no injection of purge air. For the sake of clarity, the data shown in the all of the contour plots (except the uncertainty distributions) have undergone 100 iterations of Laplacian smoothing with an under-relaxation coefficient of 0.5 in Tecplot $360^{\circ}$. The main parameters of operation are summarized in Table 1.

In the Nusselt number distribution of Figure 3 a the following observations can be made:

1) a high rate of heat transfer at the very start of the passage is justified by the start of the thermal and aerodynamic boundary layer, since it corresponds to the start of the heated rotor endwall;

2) a wedge-like region with nearly uniform heat transfer is observed close to the entrance of the passage;

3) a higher heat transfer level is recorded close to the pressure side of the leading edge of the blade that can be related to the formation of the pressure leg of the horseshoe vortex;

4) the Nusselt number increases due to flow acceleration moving closer to the throat section of the passage. 
The observations are consistent with studies from cascades (Blair, 1974), (Graziani et al., 1980), (Goldstein and Spores, 1988).

The adiabatic wall temperature distribution is shown in Figure $3 \mathrm{~b}$ in terms of its difference to the rotor-relative total temperature at rotor inlet $T_{t, \text { rel }}$, normalized by the relative dynamic temperature at rotor inlet (see Equation 7).

$$
\Theta=\left(\mathrm{T}_{\mathrm{aw}}-\mathrm{T}_{\mathrm{t}, \mathrm{rel}}\right) / \frac{\mathrm{w}_{\infty, \text { in }}{ }^{2}}{2 \cdot \mathrm{C}_{\mathrm{p}, \text { in }}},
$$

Where $\mathrm{w}_{\infty \text {,in }}$ is the relative velocity at rotor inlet and $\mathrm{C}_{\mathrm{p} \text {,in }}$ is the specific heat at constant pressure for air at the static conditions at rotor inlet. As expected, the adiabatic wall temperature drops while the flow accelerates and expands. The triangular region in the middle of the passage inlet marks the partition between the suction and pressure legs of the horseshoe vortices, while the shape of the contours seem to correspond to the migration of the passage vortex towards the suction side of the blade.

\section{Uncertainty analysis}

The propagation of the uncertainties to the final results is evaluated by successively perturbing the input parameters of the processing software according to the method described by Moffat (1988). In particular, the main relative contributions to the mean square error averaged over the passage come from:

- conductive losses (70\%);

- variability of the scaling factor $S_{\mathrm{q}}$ with different power levels $(22 \%)$;

- surface temperature (6\%).

The conduction losses $\dot{q}_{\text {cond }}$ - evaluated according to Equation 5 and discussed above - are varied between the minimum and maximum values recorded: respectively $0 \%$ and $9 \%$ of the total local heat flux $\dot{\mathrm{q}}{ }_{\mathrm{el}}$.

The correction factor $\mathrm{S}_{\mathrm{q}}$ variability is within $3.7 \%$ on average over the whole endwall surface, from tests performed in the range $0.9 \mathrm{~kW} / \mathrm{m}^{2}$ to $2.3 \mathrm{~kW} / \mathrm{m}^{2}$.

The remaining contributions come from uncertainties on the surface emissivity $\varepsilon=0.98 \pm 2 \%$, electrical power $( \pm 1.6 \%)$ and relative total temperature at rotor inlet $( \pm 1 \mathrm{~K})$.

\section{Effect of purge air on heat transfer quantities}

Results are presented for the two injection rate settings of $0.8 \%$ and $1.2 \%$ referred to the reference case with no purge air injection $(0.0 \%)$. Particularly, variations in Nusselt number and adiabatic wall temperatures are shown respectively in terms of percentage of the reference Nusselt number (Figure 5a) and (Figure 6a) and a non-dimensional temperature difference $\theta$ (Figure 5b) and (Figure 6b). The two quantities are defined as:

$$
\begin{gathered}
\Delta \mathrm{Nu}=\frac{\mathrm{Nu}-\mathrm{Nu}_{0.0 \%}}{\mathrm{Nu}_{0.0 \%}} \cdot 100 \\
\theta=\frac{\mathrm{T}_{\mathrm{aw}}-\mathrm{T}_{\mathrm{aw}, 0.0 \%}}{\mathrm{~T}_{\mathrm{t}, \text { rel,purge }}-\mathrm{T}_{\mathrm{t}, \text { rel,MAIN }}}
\end{gathered}
$$

In Equation 9, $\mathrm{T}_{\mathrm{aw}}$ is the local adiabatic wall temperature for the test case of interest, $\mathrm{T}_{\mathrm{aw}, 0.0 \%}$ is the adiabatic wall temperature of the reference test case with no purge flow injection, $T_{t, \text { rel,purge }}$ and $T_{t, \text { rel,MAIN }}$ are respectively the rotor-relative total temperatures of the purge flow and of the main flow, obtained by means of probe measurements. Due to the operations in Equation 8 and Equation 9, the uncertainties in $\Delta \mathrm{Nu}$ and $\theta$ are higher than the ones shown in Figure 4. An analytical calculation of uncertainty propagation shows that the uncertainties in $\Delta \mathrm{Nu}$ are $-14 \%$ on average over the whole endwall, while the uncertainty in $\theta$ is shown in Figure 5. 


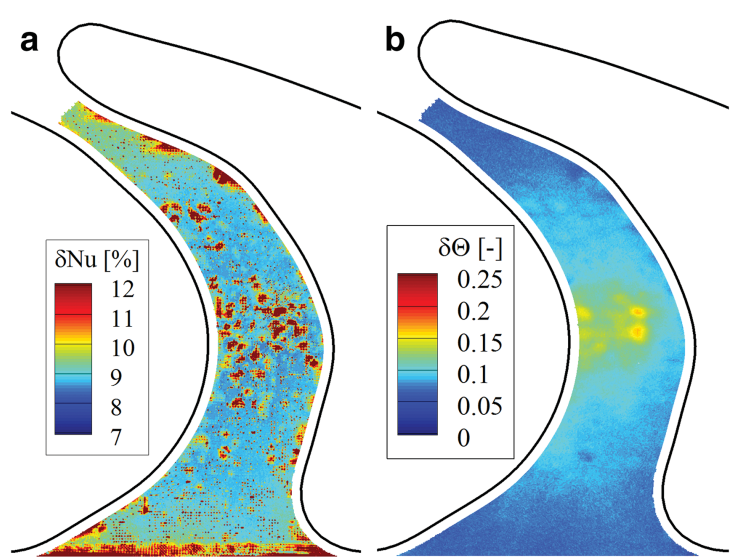

Figure 4. a) Experimental uncertainty distributions for Nusselt number; b) non-dimensional adiabatic wall temperature.

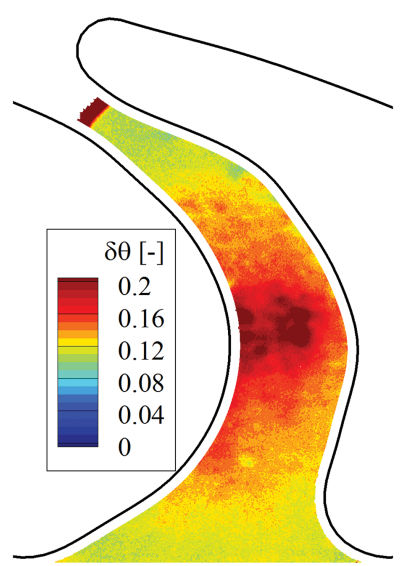

Figure 5. Experimental uncertainty distributions for non-dimensional adiabatic wall temperature difference.

The definition (9) enables a qualitative assessment of the cooling effect of the purge flow over the endwall. In the current study, density ratios are not representative of cooling conditions in actual engines, being in the order of 1 . Furthermore, in this experiment, the cavity flow presents a rotorrelative total temperature higher than the one of the main flow by $(2 \pm 0.2) \mathrm{K}$.

Variations of Nusselt number on a point-wise basis are shown in Figure 6a and Figure 7a, respectively for IR $0.8 \%$ and IR $1.2 \%$, while laterally averaged profiles of Nusselt numbers are presented for all cases in Figure 8a.

Differences in Nusselt number induced by different rates of purge air injection are generally within the measurement uncertainties both on a local and on a circumferentially averaged basis. Nonetheless, at the very inlet of the passage, close to the suction side of the rotor blade, pairs of islands presenting increases up to $20 \%$ of the reference case and decreases of the order of $5 \%$ are consistently observed in both Nusselt number distributions recorded for IR0.8\% and IR1.2\%. The patterns suggest a strengthening of the suction side leg of the horseshoe vortex producing an increase of heat transfer due to the downwash acceleration and a milder decrease corresponding to the upwash acceleration. Similar effects have been observed in turbulent boundary layers perturbed by longitudinal vortices (Eibeck and Eaton, 1987). Moreover, increases up to $20 \%$ are also recorded

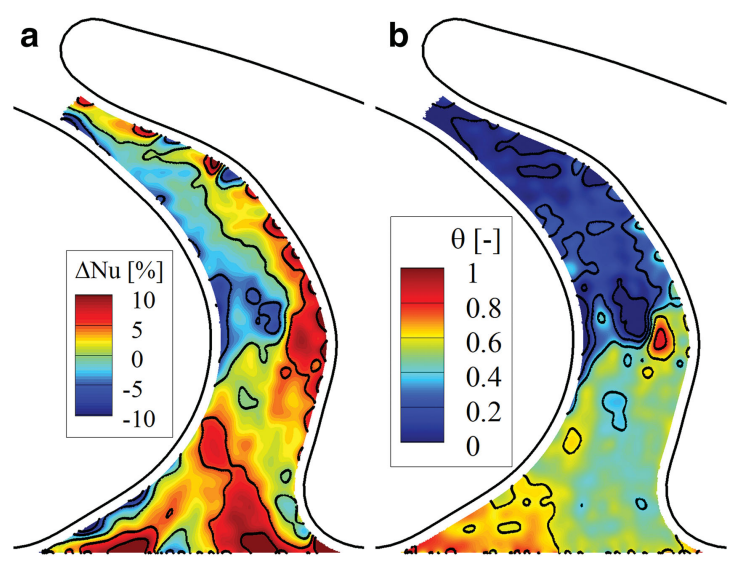

Figure 6. a) Comparison between reference case (IR $=0.0 \%)$ and $\mathrm{IR}=0.8 \%$. Nusselt number relative difference; b) non-dimensional adiabatic wall temperature difference Equation 9.

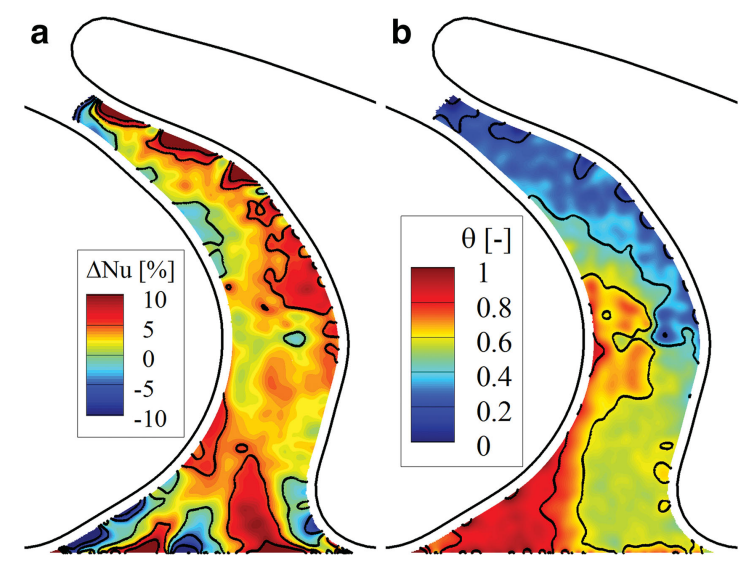

Figure 7. a) comparison between reference case (IR $=0.0 \%)$ and IR $=1.2 \%$. Nusselt number relative difference; b) non-dimensional adiabatic wall temperature difference Equation 9. 

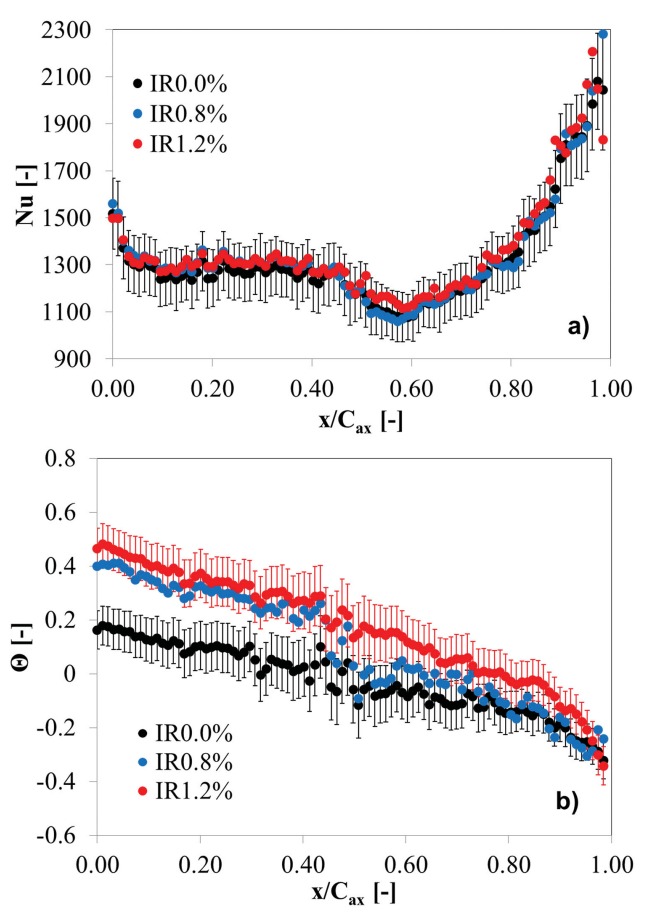

Figure 8. a) Circumferentially averaged Nusselt number for all test cases; b) circumferentially averaged non-dimensional adiabatic wall temperature (see Equation 7).

Error bars represent a 95\% confidence interval. closer to the pressure side of the blade and affecting a wider area spanning towards the suction side. This can be related to the strengthening of the passage vortex due to the entrainment of purge flow. Additionally, it is worth noting that the area of Nusselt number increase in the proximity of the pressure side of the blade has a lesser axial extent in the IR1.2\% case. This suggests an earlier lift-off of the passage vortex due to the higher radial momentum of the purge flow.

The adiabatic wall temperature distributions underline for both cases (Figure 6b) and (Figure 7b) how the purge flow is most effective as coolant in the proximity of the suction side of the rotor blade, as expected. In this location, the effect of purge air manifests itself as a local increase of the adiabatic wall temperature. Respectively, the increase is of 0.67 times the difference between the rotor-relative total temperatures of the cavity flow and the main flow for an IR $0.8 \%$ and of 0.82 times for an IR1.2\%.

The local character of the adiabatic wall temperature variation highlights how the purge air has a potential application as coolant for specific rotor endwall locations (i.e., inlet of the passage towards the suction side of the blade).

On a circumferentially averaged basis, Figure 8a shows negligible impact of the purge air injection, while differences are still well distinguishable in Figure 8b, especially towards the inlet and until $-30 \%$ of the rotor blade axial chord $\mathrm{C}_{\mathrm{ax}}$.

\section{Comparison with numerical predictions}

Both predictions (Figure 9b) and experimental data (Figure 9a) for IR0.8\% show the following features consistently:

- a high heat transfer region on the pressure side of the passage due to the horseshoe vortex formation;

- the increase of Nusselt number due to flow acceleration;

- two regions of lower heat transfer close to the inlet and downstream of the migration of the passage vortex towards the suction side of the passage.

Notice that the start of the boundary layer is not present in the CFD results, because the uniform heat flux boundary condition is imposed from further upstream $\left(2 \%\right.$ of $\left.\mathrm{C}_{\mathrm{ax}}\right)$ in the model, compared to the start of the heated platform used in the experiments. This was necessary to overcome difficulties in meshing the cavity/main flow path interface.

The general underestimation of the heat transfer level is attributed to the effect of wall roughness, not properly captured by the simulations. An estimation of the non-dimensional sandgrain roughness

$$
\mathrm{k}_{\mathrm{s}}^{+}=\frac{\mathrm{k}_{\mathrm{s}} \cdot \mathrm{w}}{\mathrm{v}} \cdot \sqrt{\frac{\mathrm{f}}{2}}
$$

can be given based on the measured sandgrain roughness $\mathrm{k}_{\mathrm{s}}$, the mass-averaged relative velocities $\mathrm{w}$ measured by probes, Fanning's friction factor $f$ as calculated by Chen (1979) and the kinematic 


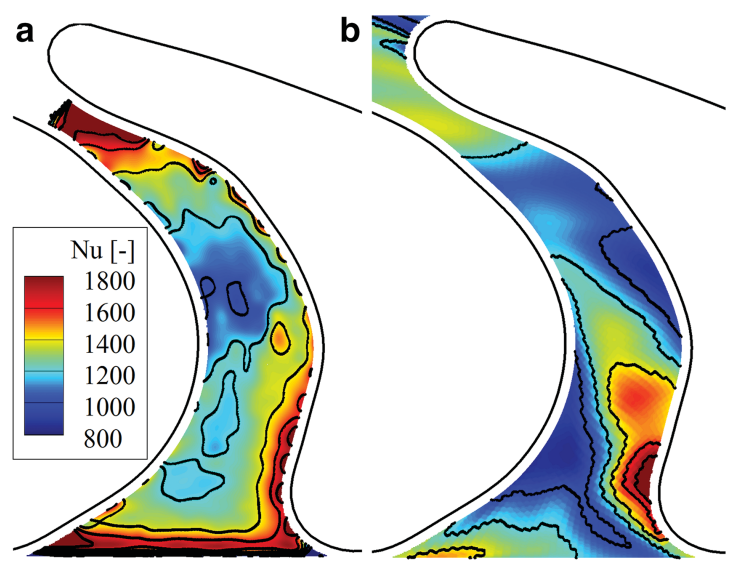

Figure 9. Comparison of Nusselt number distributions from experiments; a) transient CFD b) for IR0.8\%.

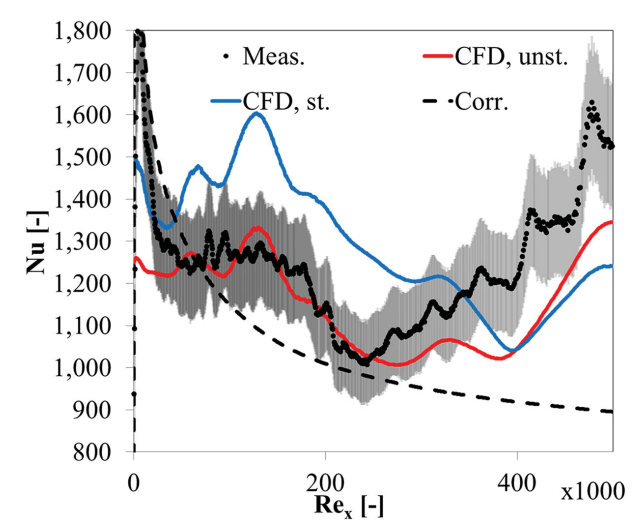

Figure 10. Circumferentially averaged Nusselt number profiles.

Shaded area represents experimental uncertainty.

viscosity of air $v$ at the mass-averaged static conditions measured at inlet and outlet of the rotor. The values are $\mathrm{k}_{\mathrm{s}}{ }^{+}-28$ at the inlet of the passage and $\mathrm{k}_{\mathrm{s}}{ }^{+}-47$ at the outlet and fall - according to the classification of Nikuradse (1933) -, in the transitionally rough regime $\left(5<\mathrm{k}_{\mathrm{s}}^{+}<70\right)$. The doubling of $\mathrm{k}_{\mathrm{s}}{ }^{+}$across the passage can explain, in particular, the divergence of the two corresponding laterally averaged Nusselt number curves in Figure 10.

The circumferentially averaged Nusselt number profiles of Figure 10 show good agreement between the experimental data and the unsteady simulations until about $50 \%$ of the axial extent of the passage. From this point on, the flow acceleration becomes of relevance and the increase in heat transfer due to the thinner boundary layer is underpredicted. The discrepancy is attributed to a not captured wall roughness effect. The steady CFD simulation tends to overpredict the heat transfer significantly $(20-30 \%)$. The comparison is completed with a flat plate correlation for turbulent boundary layers on surfaces with uniform heat flux:

$$
\mathrm{Nu}=0.03 \cdot \operatorname{Pr}^{0.6} \cdot \operatorname{Re}_{\mathrm{x}}{ }^{0.8} \cdot \mathrm{C}_{\mathrm{ax}} / \mathrm{x}
$$

The correlation matches the experiments in the initial part of the passage (until $\sim 15-20 \%$ of its axial extent), until secondary flows and flow acceleration occur.

\section{Conclusions}

The main conclusions of the current work can be summarized as follows:

1) the spatial resolution and sensitivity of the IR-based technique developed for this work are sufficient to detect local variations in heat load due to flow features and the effects of purge air injection on the adiabatic wall temperature on the rotor endwall;

2) overall, the effect of purge flow on the Nusselt number distribution falls within the measurement uncertainty. However, the observed trends show a change in the secondary flow patterns and, particularly, a strengthening effect of purge air injection on the horseshoe vortex and passage vortex;

3) purge flow has a relevant effect on the heat fluxes close to the suction side of the rotor passage, up to $-30 \%$ of its axial extent. It does alter, in fact, the adiabatic wall temperature by bringing it closer to its own rotor-relative total temperature. An increase in the local adiabatic wall temperature of $67 \%$ of the temperature difference between cavity flow and main flow is reported for an IR of $0.8 \%$. The increase grows to $82 \%$ for an IR of $1.2 \%$. These results suggest that purge flow can effectively be used as rotor platform coolant in the specific region of the passage close to the suction side of the rotor blade; 
4) unsteady heat transfer predictions show agreement within the experimental uncertainty until $-50 \%$ of the axial extent of the passage. Steady state simulations, on the other hand, overpredict heat transfer by up to $20-30 \%$. The computational effort of running unsteady simulations is paid off by greater accuracy in the predictions.

\section{Nomenclature}
A endwall surface area
$\mathrm{C}_{\mathrm{p}}$ specific heat of air
$\mathrm{C}_{\mathrm{ax}}$ axial chord of rotor blade measured at midspan
d RTD sensor distance from endwall surface
$\mathrm{h}$ heat transfer coefficient
i current
IR injection ratio
$\mathrm{k}$ th. cond. of air at rotor inlet static conditions
$\mathrm{k}_{\mathrm{s}}$ equivalent sandgrain roughness
$\mathrm{k}_{\mathrm{s}}^{+}$non-dimensional equivalent sandgrain roughness
$\dot{\mathrm{m}}$ mass flow rate

$\mathrm{Nu}$ Nusselt number based on axial chord and thermal conductivity of air

P electrical power

Pr Prandtl number

q" heat flux

$r$ turbulent recovery factor

Re Reynolds number

$S_{\mathrm{q}}$ heat flux scaling factor

$\mathrm{T}$ temperature

$\mathrm{u}_{\tau}$ friction velocity

$\mathrm{V}$ voltage

$\mathrm{w}_{\infty}$ mass-averaged, rotor-relative flow velocity

$\mathrm{y}^{+} \quad 1^{\text {st }}$ cell height, non-dim. by viscous unit

\section{Greek}

$\varepsilon$ surface emissivity

$\sigma$ Stefan-Boltzmann constant

$\theta \quad \theta=\frac{\mathrm{T}_{\mathrm{aw}}-\mathrm{T}_{\mathrm{aw}, 0.0 \%}}{\mathrm{~T}_{\mathrm{t}, \mathrm{rel}, \text { purge }}-\mathrm{T}_{\mathrm{t}, \mathrm{rel}, \mathrm{MAIN}}}$

$\Theta \Theta=\left(T_{a w}-T_{t, \text { rel }}\right) / \frac{w_{\infty, \text { in }}{ }^{2}}{2 \cdot C_{p, \text { in }}}$

$\checkmark$ kinematic viscosity 


\section{Subscripts}

$\begin{array}{ll}\text { aw } & \text { adiabatic wall } \\ \text { B } & \text { by-pass flow } \\ \text { cond } & \text { conductive heat flux } \\ \text { conv } & \text { convective heat flux } \\ \text { el } & \text { electric heat flux generated by Joule effect } \\ \text { ex } & \text { at rotor outlet } \\ \text { in } & \text { at rotor inlet } \\ \text { MAIN } & \text { main flow } \\ \text { rad } & \text { radiative heat flux } \\ \text { S } & \text { leakage flow } \\ \text { sub } & \text { substrate } \\ \text { t,rel } & \text { total rotor-relative } \\ \text { w } & \text { wall } \\ \text { x } & \text { axial coordinate }\end{array}$

\section{Funding sources}

Siemens AG. MTU Aero Engines AG.

\section{Competing interests}

All authors declare that they have no conflict of interest.

\section{References}

Abhari R. S. and Epstein A. (1992). An experimental study of film cooling in a rotating transonic turbine. ASME 1992 International Gas Turbine and Aeroengine Congress and Exposition, Cologne, Germany, 1-4 June 1992, International Gas Turbine Institute. V004T09A018. https://doi.org/10.1115/92-GT-201.

Abhari R., Guenette G., Epstein A., and Giles M. (1991). Comparison of time-resolved turbine rotor blade heat transfer measurements and numerical calculations. ASME 1991 International Gas Turbine and Aeroengine Congress and Exposition, Orlando, Florida, USA, 3-6 June 1991, International Gas Turbine Institute. V004T09A018. https://doi.org/10.1115/91GT-268.

Blair M. (1974). An experimental study of heat transfer and film cooling on large-scale turbine endwalls. ASME 1974 International Gas Turbine Conference and Products Show, Zurich, Switzerland, 30 March-4 April 1974, International Gas Turbine Institute. V01AT01A033. https://doi.org/10.1115/74-GT-33.

Blair M. F. (1992). An experimental study of heat transfer in a large-scale turbine rotor passage. ASME 1992 International Gas Turbine and Aeroengine Congress and Exposition, Cologne, Germany, 1-4 June 1992, International Gas Turbine Institute. V004T09A012. https://doi.org/10.1115/92-GT-195.

Chen N. H. (1979). An explicit equation for friction factor in pipe. Industrial \& Engineering Chemistry Fundamentals. 18 (3): 296-297. https://doi.org/10.1021/i160071a019.

Dénos R. and Paniagua G. (2002). Influence of the hub endwall cavity flow on the time-averaged and time-resolved aerothermodynamics of an axial HP turbine stage. ASME Turbo Expo 2002: Power for Land, Sea, and Air, Amsterdam, The Netherlands, 3-6 June 2002, International Gas Turbine Institute. 207-217. https://doi.org/10.1115/GT2002-30185.

Dunn M. G., Rae W. J., and Holt J. L. (1984a). Measurement and analyses of heat flux data in a turbine stage: Part IDescription of experimental apparatus and data analysis. Journal of Engineering for Gas Turbines and Power. 106 (1): 229233. https://doi.org/10.1115/1.3239539. 
Dunn M. G., Rae W. J., and Holt J. L. (1984b). Measurement and analyses of heat flux data in a turbine stage: Part IIDiscussion of results and comparison with predictions. Journal of Engineering for Gas Turbines and Power. 106 (1): 234240. https://doi.org/10.1115/1.3239540.

Eibeck P. and Eaton J. (1987). Heat transfer effects of a longitudinal vortex embedded in a turbulent boundary layer. Journal of Heat Transfer. 109 (1): 16-24. https://doi.org/10.1115/1.3248039.

Faugeras O., Luong Q.-T., and Papadopoulo T. (2004). The Geometry of Multiple Images: The Laws that Govern the Formation of Multiple Images of a Scene and Some of Their Applications. Cambridge, Massachussets (USA): MIT press.

Gao Z., Narzary D., and Han J.-C. (2009). Turbine blade platform film cooling with typical stator-rotor purge flow and discrete-hole film cooling. Journal of Turbomachinery. 131 (4): 041004. https://doi.org/10.1115/1.3068327.

Goldstein R. J. and Spores R. A. (1988). Turbulent transport on the endwall in the region between adjacent turbine blades. Journal of Heat Transfer. 110 (4a): 862-869. https://doi.org/10.1115/1.3250586.

Graziani R., Blair M. F., Taylor J., and Mayle R. (1980). An experimental study of endwall and airfoil surface heat transfer in a large scale turbine blade cascade. Journal of Engineering for Power. 102 (2): 257-267. https://doi.org/10.1115/1.3230246.

Green B. R., Mathison R. M., and Dunn M. G. (2013a). Time-averaged and time-accurate aerodynamic effects of forward rotor cavity purge flow for a high-pressure turbine-Part I: Analytical and experimental comparisons. Journal of Turbomachinery. 136 (1): 011004 . https://doi.org/10.1115/1.4024774.

Green B. R., Mathison R. M., and Dunn M. G. (2013b). Time-averaged and time-accurate aerodynamic effects of rotor purge flow for a modern, one and one-half stage high-pressure turbine-Part II: Analytical flow field analysis. Journal of Turbomachinery. 136 (1): 011009. https://doi.org/10.1115/1.4024776.

Jenny P., Abhari R. S., Rose M. G., Brettschneider M., Engel K., et al. (2013). Unsteady rotor hub passage vortex behavior in the presence of purge flow in an axial low pressure turbine. Journal of Turbomachinery. 135 (5): 051022. https://doi.org/ $10.1115 / 1.4007837$

Laveau B., Abhari R. S., Crawford M. E., and Lutum E. (2014). High resolution heat transfer measurements on the stator endwall of an axial turbine. Journal of Turbomachinery. 137 (4): 041005. https://doi.org/10.1115/1.4028431.

Lynch S. P., Sundaram N., Thole K. A., Kohli A., and Lehane C. (2011). Heat transfer for a turbine blade with nonaxisymmetric endwall contouring. Journal of Turbomachinery. 133 (1): 011019. https://doi.org/10.1115/1.4000542.

Lynch S. P. and Thole K. A. (2015). Heat transfer and film cooling on a contoured blade endwall with platform gap leakage. ASME Turbo Expo 2015: Turbine Technical Conference and Exposition, Montreal, Quebec, Canada, 15-19 June 2015, International Gas Turbine Institute. V05BT12A037. https://doi.org/10.1115/GT2015-43301.

Moffat R. J. (1988). Describing the uncertainties in experimental results. Experimental thermal and fluid science. 1 (1): 3-17. https://doi.org/10.1016/0894-1777(88)90043-X.

Nikuradse J. (1933). Laws of flow in rough pipes. Forsch Ing-Wes. 4 (1): 44. https://doi.org/10.1007/BF02716946.

Ong J., Miller R. J., and Uchida S. (2012). The effect of coolant injection on the endwall flow of a high pressure turbine. Journal of Turbomachinery. 134 (5): 051003. https://doi.org/10.1115/1.4003838.

Paniagua G., Dénos R., and Almeida S. (2004). Effect of the hub endwall cavity flow on the flow-field of a transonic highpressure turbine. Journal of Turbomachinery. 126 (4): 578-586. https://doi.org/10.1115/1.1791644.

Regina K., Kalfas A., Abhari R., Lohaus A., Voelker S., et al. (2014). Aerodynamic robustness of end wall contouring against rim seal purge flow. ASME Turbo Expo 2014: Turbine Technical Conference and Exposition, Düsseldorf, Germany, 16-20 June 2014, International Gas Turbine Institute. V02CT38A027. https://doi.org/10.1115/GT2014-26007.

Reid K., Denton J., Pullan G., Curtis E., and Longley J. (2006). The effect of stator-rotor hub sealing flow on the mainstream aerodynamics of a turbine. ASME Turbo Expo 2006: Power for Land, Sea, and Air, Barcelona, Spain, 8-11 May 2006, International Gas Turbine Institute. 789-798. https://doi.org/10.1115/GT2006-90838.

Schädler R., Kalfas A. I., Abhari R. S., Schmid G., and Völker S. S. (2016). Modulation and radial migration of turbine hub cavity modes by the rim seal purge flow. Journal of Turbomachinery. 139 (1): 011011. https://doi.org/10.1115/1.4034416.

Schuepbach P., Abhari R. S., Rose M. G., Germain T., Raab I., et al. (2010). Effects of suction and injection purge-flow on the secondary flow structures of a high-work turbine. Journal of Turbomachinery. 132 (2): 021021. https://doi.org/10.1115/ 1.4000485 .

Wright L. M., Blake S. A., Rhee D.-H., and Han J.-C. (2009). Effect of upstream wake with vortex on turbine blade platform film cooling with simulated stator-rotor purge flow. Journal of Turbomachinery. 131 (2): 021017. https://doi.org/ $10.1115 / 1.2952365$. 